\title{
O ensino de Língua Portuguesa e a noção de prática social: uma análise da Base Nacional Comum Curricular
}

Larissa Malu dos Santos ${ }^{\mathrm{i}}$

\begin{abstract}
RESUMO
As diversas tendências pedagógicas que atravessam o país, assim como as teorias relativas ao ensino de língua, procuraram alçar, a partir do século $\mathrm{XX}$, perspectivas de educação que tivessem em vista as práticas sociais dos sujeitos. Esse conceito, portanto, parece pairar de forma bastante alargada dentro do âmbito do fazer pedagógico, sendo possível depreendê-lo da Base Nacional Comum Curricular (BRASIL, 2017). Tendo por objetivo evidenciar a forma como o conceito de prática social, embora aparentemente isomorfo, apresenta ideais formativos distintos, realizaremos primeiramente uma análise das principais tendências pedagógicas presentes no país, para, posteriormente, analisarmos a BNCC. Tomando como escopo teórico o materialismo histórico-dialético, procuraremos discutir como os fundamentos de tais tendências e do documento em questão acabam prospectando diferentes noções do que seja tal prática social.
\end{abstract}

Palavras-chave: Ensino de língua; Prática social; Base Nacional Comum Curricular.

\begin{abstract}
The different pedagogical currents that cross Brazil, as well as theories related to language teaching, sought to raise, since the twentieth century, educational perspectives that looked at the subjects' social practices. This concept, therefore, seems to hover quite widely within the scope of pedagogical practice, and it may be possible to understand it within the Common National Curricular Base (BRASIL, 2017). To highlight the way that the concept of social practice, although apparently isomorphic, presents different formative ideals, I will first carry out an analysis of the main pedagogical currents present in the country, to later analyze the BNCC. Taking historical-dialectical materialism as a theoretical scope, I will try to discuss how the foundations of such currents and the document in question end up projecting different notions of what such a social practice is.
\end{abstract}

Keywords: Language teaching; Social practice; Common National Curricular Base.

\footnotetext{
${ }^{i}$ Mestra em Linguística pelo Programa de Pós-Graduação em Linguística da Universidade Federal de Santa Catarina. Atualmente, doutoranda pelo Programa de Pós-Graduação em Linguística da UFSC, na área de concentração em Linguística Aplicada. Vinculada ao Núcleo de Estudos em Linguística Aplicada (NELA) da Universidade Federal de Santa Catarina e participante do Grupo de Pesquisa "Cultura Escrita e Escolarização". | https://orcid.org/0000-0002-2409-9434 | larissamalu@ @otmail.com
} 


\section{INTRODUÇÃO}

É certo que, desde meados do século XX, a noção de escola e sua função como instituição têm sido questionadas por modelos e abordagens que se colocam como alternativas ao que se denomina Escola Tradicional. Se outrora o espaço escolar fora compreendido como um lugar de mera transmissão do conhecimento, em que o aluno seria aquele que deveria memorizar todos os saberes tomados como os mais ilustres, para poder ele sair daquilo que se compreendia como ignorância (SAVIANI, 2012 [1983]), as perspectivas mais recentes de ensino têm buscado, em alguma medida, distanciar-se de tais acepções do que seja a escola.

O ensino de Língua Portuguesa (LP), nesse cenário, também foi ganhando outros contornos. Sabemos que a Escola Tradicional repercute dentro do âmbito do ensino linguístico por meio da imposição do ensino da gramática, como sendo aquele que deve ocupar o centro do processo educativo em linguagem. Tal ensino, certamente, ainda se faz presente em larga escala nas mais diversas escolas deste país. No entanto, na esteira das discussões sobre a concepção de escola, a educação linguística também fora colocada em xeque nos últimos anos. Dentre alguns dos autores que se manifestaram, na década de 1970, em contraposição a esse modelo conservador, podemos citar João Wanderley Geraldi e Rodolfo Ilari, os quais, como nos aponta Britto (2003, p. 18), procuraram alçar "um movimento reformador que questionava o privilégio da visão normativista e sustentava o respeito às variedades linguísticas e a aprendizagem a partir do uso". Podemos ver aí, portanto, uma tentativa de inserção de uma nova concepção de ensino linguístico que passa a tomar a língua não mais como algo puramente normativo, mas como um produto que emerge nas/das relações sociais.

$\mathrm{O}$ que vemos em comum em tais questionamentos sobre o que se toma como ensino escolar - e, também especificamente, como ensino de língua - é a necessidade que urge de que a escola se torne um espaço de formação não apenas voltado para o mercado de trabalho, ou para tirar os sujeitos do que se pudera considerar como ignorância, mas como uma instituição que promova uma formação voltada para a prática social desses sujeitos. Quer dizer, a discussão privilegia a escola como espaço em que a preocupação primeira seja relacionar os conteúdos trabalhados em sala de aula 
com aquilo que é da ordem do social, da vida propriamente dita. Uma relação entre teoria e prática, portanto.

Ao tomarmos o conceito de práxis (GRAMSCI, 1968) para refletir sobre tal relação (teoria e prática), percebemos que, para o materialismo histórico-dialético escopo teórico-filosófico deste artigo -, a noção de prática social compreende que tal vinculação apenas pode se concretizar de forma dialética, e que, para compreendermos de fato a realidade - em sua totalidade e não de forma fetichista (MARX, 2017 [1867]) - o conhecimento ocupa lugar bastante importante, já que é apenas por meio da possibilidade de abstração que é possível compreendermos subjetivamente o mundo e agirmos nele de forma objetiva, com o intuito último de transformá-lo (TONET, 2013). Quando analisamos, no entanto, as diversas tendências pedagógicas e os próprios documentos oficiais que foram balizando a educação ao longo dos séculos XX e XXI, observamos que, na realidade, o conceito de prática social é também tomado a partir de outras fundamentações, o que acaba gerando, portanto, uma polissemia para tal termo, já que embasado por diferentes perspectivas filosóficas e teóricas, de forma que tal relação que aqui apontamos - entre teoria e prática - nem sempre ocupa o centro do que se propõe para o ensino.

Assim, compreendendo que o termo prática social assume distintas acepções dentro do campo pedagógico - e, portanto, no que diz respeito ao ensino de língua -, procuraremos evidenciar, ao longo deste artigo, a forma como tal conceito aparece nas diferentes e principais teorias pedagógicas que ganharam força no Brasil. Para tanto, retomaremos as seguintes perspectivas pedagógicas: a) a pedagogia tradicional; b) a pedagogia nova; c) a pedagogia tecnicista; d) a pedagogia das competências; e e) a pedagogia histórico-critica. Dentre as diversas correntes que serão apresentadas, destacamos aquela que aparece como estofo para a Base Nacional Comum Curricular (BNCC, 2017), a pedagogia das competências. Partindo desse resgate histórico, analisaremos, ao fim, a forma como o conceito de prática social aparece nas seções iniciais da BNCC (2017) e na seção específica sobre o ensino de LP nos Anos Finais do Ensino Fundamental, dado o recorte deste trabalho, qual seja: pensar de que forma o ensino linguístico é tomado na BNCC (2017) e como pode proporcionar, se ancorado no materialismo histórico-dialético, melhor compreensão e transformação da prática social na qual nos inserimos. 


\section{A NOÇÃO DE PRÁTICA SOCIAL NAS TENDÊNCIAS PEDAGÓGICAS}

Apresentamos, nesta seção, breve resgate histórico de distintas tendências pedagógicas que atravessam as proposições teóricas e metodológicas de nosso país, a partir das obras História das Ideias Pedagógicas no Brasil (2013) e Escola e Democracia (2012 [1983]), ambas de autoria de Dermeval Saviani. O autor traz, em seus textos, uma discussão sobre a forma como as teorias pedagógicas surgiram e, neste trabalho, procuraremos evidenciar de que maneira aparece a noção de prática social nessas distintas correntes. Como veremos, tal concepção está, em alguma medida, sempre presente nas tendências que, ao longo das décadas, foram tomando força, mesmo que, em algumas vezes, de forma mais central e, em outras, mais periférica. Importa salientar que muito mais do que apontar se esse conceito aparece ou não nas teorias pedagógicas de que nos valemos neste artigo, a intenção é questionar se nosso trabalho educativo como objetivo último a manutenção ou a transformação do estado de coisas, o que é possível enxergar, apenas, através de um olhar mais atento para os embasamentos filosóficos e teóricos que subjazem aquilo que tomamos como fio condutor de nosso trabalho.

\subsection{A pedagogia tradicional}

Certamente a análise da pedagogia dita tradicional poderá causar algum espanto ao leitor. Isso porque é quase consenso - especialmente dentro do universo acadêmico que tal perspectiva de ensino pouco alça aos estudantes uma compreensão e uma formação que de fato coloquem as práticas desses sujeitos no centro da ação em sala de aula. Todavia, torna-se relevante retomar os pressupostos de tal corrente, posto que paira ali também uma compreensão acerca da relação entre o que é objeto de ensino e o que os estudantes precisariam para integrarem a vida em sociedade.

Os moldes tradicionais nascem em um momento histórico bastante importante: pós-proclamação da Independência do Brasil, em 1822, e prospecção - em nível mundial - de um modo de viver baseado na estrutura capitalista. Por ambas as razões, 
fazia-se necessário, à época, que os sujeitos fossem tomados como cidadãos livres. Os antigos servos e escravos precisariam se ajustar à nova forma de viver em sociedade, a qual propagava ideários que reforçavam a noção de liberdade ${ }^{1}$. Tem-se, portanto, nesse momento histórico, uma noção essencialista dos homens, a qual irá se materializar, no âmbito educacional, na compreensão de que todos os homens são iguais e essencialmente livres, e que cabe aos propósitos da escola retirar os indivíduos da ignorância para que possam eles exercer sua cidadania (SAVIANI, 2012 [1983]). Nesse sentido, a escola teria a função de difundir o conhecimento e os rudimentos do saber que a burguesia considerava imprescindíveis para que tal ignorância fosse afastada, o que se concretizaria sobretudo por meio da transmissão de conteúdos por parte do professor. Este, sendo "o artífice dessa grande obra" (SAVIANI, 2012 [1983] p. 6), ficaria encarregado de transmitir, "segundo uma gradação lógica, o acervo cultural aos alunos" (SAVIANI, 2012 [1983] p. 6), de modo que, aos estudantes, caberia apenas assimilar tais conhecimentos. Dentre os conteúdos que, desde o princípio, ganharam destaque, poderíamos citar aqueles relativos aos conhecimentos básicos de leitura, de escrita, de matemática e da moral cristã (SAVIANI, 2013). Quer dizer, conhecimentos que eram fundamentais, naquele momento, para que os alunos pudessem se adequar à sociedade que se consolidava.

Nesse sentido, podemos afirmar que, de alguma forma, o espaço escolar tinha aí alguma vinculação com a vida dos estudantes, com suas práticas sociais, já que seus ideários apontavam a necessidade de formar os indivíduos a fim de que eles pudessem participar da vida em sociedade, exercendo seus direitos. Saviani (2012 [1983]) nos aponta, inclusive, o caráter revolucionário que tinha, à época, a Escola Tradicional, mas como, ao fim, ela acaba se tornando um modelo que apenas mantém o estado de coisas.

Calcada na filosofia da essência (SUCHODOLSKI, 1972) e numa perspectiva epistemológica positivista (LÖWY, 2013), a pedagogia tradicional não poderia, como já supúnhamos, alçar uma verdadeira compreensão da prática social que é imposta, já que seus ideários apontam apenas para uma necessidade de adequação dos indivíduos para que o modus operandi seja mantido, e não transformado. No entanto, é possível afirmar também que há, nessa perspectiva, uma tentativa de relação entre as práticas e aquilo que é objeto de ensino. 


\subsection{A pedagogia nova}

Se a Escola Tradicional nasce de um movimento que compreende os homens a partir de um viés essencialista, a pedagogia nova, que ganha força em meados de 1930, pauta suas fundamentações numa perspectiva existencialista. A pedagogia da existência (SUCHODOLSKI, 1972), que agora ganha vez, aponta para a noção de que os homens são, ao contrário da concepção tradicionalista, diferentes: "com base nesse tipo de pedagogia, considera-se que os homens não são essencialmente iguais; os homens são essencialmente diferentes, e nós temos que respeitar as diferenças entre os homens" (SAVIANI, 2012 [1983], p. 41). Assim, não caberia mais separar os alunos de forma estanque, já que, para tal perspectiva, importa conhecer o estudante e tomá-lo como centro do processo educativo.

Passando, portanto, de uma tendência pedagógica que tinha o foco no professor e nos conteúdos enciclopédicos, teríamos, com a pedagogia nova, uma teoria que estabeleceria como ponto de partida e de chegada os próprios alunos. O conhecimento, aqui, está sempre em relação com aquilo que os estudantes querem e têm interesse em aprender. Importa, para essa tendência, que os estudantes aprendam sobretudo a aprender, de modo que se torna função da escola "o estímulo às observações e experiências da criança, levando-a a desenvolver o trabalho intelectual com interesse e prazerosamente, satisfazendo sua curiosidade intelectual" (SAVIANI, 2013, p. 212).

Pautada num ideário que pretende levar o 'gostoso' para a sala de aula, ou, nas palavras de Saviani (2013, p. 212) “a alegria de viver", o escolanovismo traz para o âmbito educacional uma noção de escola que deve priorizar aquilo que torne o aprendizado leve e prazeroso, de modo que os conteúdos não podem ser outros, senão aqueles relativos à vida dos sujeitos. Quer dizer, em sendo os alunos que decidem os conhecimentos a serem trabalhados em sala de aula, tais conteúdos acabam ficando, em alguma medida, restritos à vida empírica dos sujeitos, já que é dali que trazem eles indagações ou curiosidades. Podemos dizer, portanto, que há, aí, uma tentativa bastante marcada de trazer a prática social dos sujeitos para a escola, já que a vida dos estudantes ganha bastante espaço no fazer pedagógico.

Embora seja bastante evidente a centralidade da noção de prática social para a pedagogia nova, é importante observar que, uma vez que tal corrente toma como ponto 
fulcral o que é do âmbito do cotidiano dos sujeitos, esse conceito parece tomar, aqui, uma concepção calcada na epistemologia historicista, porque envolvida com a vida empírica. Para tal fundamento, importa que nos encharquemos no rio da história (LÖWY, 2013), dando potência, portanto, àquilo que é do local e do imediato.

Tendo em vista que tomamos os pressupostos do materialismo históricodialético nesta discussão, apontamos para a problemática de tal restrição do conhecimento - relativo apenas à empiria -, já que defendemos a importância da compreensão da realidade no seu todo, na sua totalidade, para que sua transformação possa realmente ser efetivada. É necessário, portanto, que o conhecimento - não o enciclopédico, mas aquele que dá conta do que é relativo ao gênero humano (MARX, 2010) - seja o centro das discussões em sala de aula, já que é a escola o espaço que, especialmente as classes populares, possuem para de fato se apropriarem de tais objetivações elaboradas pela humanidade. Por assim dizer, embora vejamos na tendência escolanovista o conceito de prática social de forma sobressalente, vale destacar que sua acepção denota uma prática voltada para o sujeito empírico (SAVIANI, 2012), o que, como procuramos apontar ao longo da discussão, não permite uma formação humana que de fato possibilite aos estudantes a consciência de classe que é histórica e não imediata - e uma posterior mudança do status quo.

\subsection{A pedagogia tecnicista}

Nos anos de 1960, uma nova tendência começou a ganhar força. Com as já conhecidas críticas à pedagogia tradicional e com o declínio da pedagogia nova, que não conseguia atingir os ideários aos quais se propunha, nasce uma tendência fortemente relacionada ao cenário político do país. Instaurado o Regime Militar e difundida a ideia de desenvolvimento do Brasil, que precisava decolar a qualquer custo, a pedagogia tecnicista surge para que uma concepção de escola voltada para o mercado de trabalho pudesse ser instaurada.

Baseando-se em fundamentações do taylorismo, do fordismo e do behaviorismo (SAVIANI, 2013), o tecnicismo urge pregando a necessidade de o espaço escolar voltar-se para a vida operativa dos sujeitos. Preocupada em formar os cidadãos para a vida laboral, tal tendência voltava-se para a objetividade que deveria ter a escola, de 
modo a formar os estudantes para questões práticas. Se a Escola Nova pregava o aprender a aprender, aqui se tem um novo postulado: aprender a fazer. Para esse modelo, o foco não estaria nem nos professores, tal como na Escola Tradicional, nem nos estudantes, a exemplo do escolanovismo; na pedagogia tecnicista, ambos tomam uma "posição secundária", sendo meros "executores de um processo cuja concepção, planejamento, coordenação e controle ficam a cargo de especialistas supostamente habilitados, neutros, objetivos, imparciais" (SAVIANI, 2013, p. 382). Assim, quem define que meios serão utilizados em sala de aula é o próprio processo, já que tanto docentes quanto discentes estão a serviço de terceiros, os quais, acredita-se, sabem o que é melhor para a nação e, portanto, para a educação, já que esta deve sobretudo servir ao progresso do país.

Evidentemente, não vimos nessa corrente qualquer preocupação nítida com a formação humana dos estudantes, mas há, sim, uma concepção de prática social aí presente, já que a escola se volta para a vida dos indivíduos. Ou melhor: volta-se para a vida laboral dos homens e mulheres que, eventualmente, serão inseridos no mercado de trabalho. Nesse sentido, todas as questões do âmbito da abstração teórica, da subjetividade, são eximidas do processo educativo, que acaba centrando-se apenas naquilo que é do âmbito da objetividade, da operatividade. Por assim dizer, podemos afirmar que a prática social que aqui aparece está bastante desvinculada de um projeto que de fato possibilite aos estudantes uma consciência teórica do mundo, já que a relação entre teoria e prática a que se pudera aspirar fica, enfim, restrita apenas ao segundo campo.

\subsection{A pedagogia das competências}

A tendência pedagógica das competências surge, certamente, junto ao movimento das teorias que procuram colocar-se como alternativas à pedagogia tradicional. Tendo como grande nome dessa corrente Phillipe Perrenoud, podemos citar sua obra Construir as competências desde a escola (1999) como aquela que funda tal perspectiva. Dentre as assertivas que Perrenoud (1999) busca acentuar em seus escritos, apontamos aquela relativa à necessidade de o espaço escolar tomar para si os chamados métodos ativos, juntamente à ideia de que os alunos possam aprender fazendo. 
Para essa pedagogia, a concepção de competência ganha um foco bastante marcado. Segundo Perrenoud (1999, p. 7), tal noção pode ser compreendida como "uma capacidade de agir eficazmente em um determinado tipo de situação, apoiada em conhecimentos, mas sem limitar-se a eles”. Assim, para tal corrente, os alunos apenas poderão de fato participar socialmente a partir do desenvolvimento de tais competências. O conhecimento, aqui, ganha um lugar bem específico, já que é ele apenas um acessório para a competência. Nas palavras de Perrenoud (1999, p. 8): "as competências manifestadas por ações não são, em si, conhecimentos; elas utilizam, integram, ou mobilizam tais conhecimentos". Nesse sentido, as competências ganham o foco principal no ensino, enquanto o conteúdo, além de ser secundarizado, diz respeito a uma dimensão mais ampla - e não científica, epistemológica -, calcado sobretudo nas necessidades dos estudantes. A respeito de tal tendência pedagógica, Duarte nos afirma que:

\begin{abstract}
O caráter adaptativo dessa pedagogia está bem evidente. Trata-se de preparar os indivíduos, formando neles as competências necessárias à condição de desempregado, deficiente, mãe solteira etc. Aos educadores caberia conhecer a realidade social não para fazer a crítica a essa realidade e construir uma educação comprometida com as lutas por uma transformação social radical, mas sim para saber melhor quais competências a realidade social está exigindo dos indivíduos. (2008, p. 12)
\end{abstract}

Duarte (2008) apresenta, nesse sentido, a forma como a pedagogia das competências se assemelha sobremaneira à pedagogia nova, já que ambas prezam pelo caráter ativo da educação, o qual irá tomar o sujeito como peça central do trabalho em sala de aula. Para ambas as perspectivas, "são mais desejáveis as aprendizagens que o indivíduo realiza por si mesmo, nas quais está ausente a transmissão, por outros indivíduos, de conhecimentos e experiências" (DUARTE, 2008, p. 7) do que propriamente a apropriação desses conteúdos por parte dos estudantes. É importante destacar, também, que há, igualmente, na perspectiva das competências, uma relação com o tecnicismo, já que, para a pedagogia de Perrenoud, o lema que rege a educação é que os alunos aprendam a fazer. Ser 'competente', ou seja, ter construído as competências impostas como necessárias para se viver em sociedade, implica estar preparado para realizar atividades que permeiam a vida dos sujeitos. E nada mais. Tal 
como nos aponta Duarte (2008): o caráter adaptativo dessa tendência nos é bastante claro.

Ao localizarmos, enfim, a noção de prática social nesse ideário, vimos como ela ocupa uma centralidade semelhante àquela anteriormente exposta: tal como no tecnicismo, a preocupação com a vida em sociedade dos estudantes é relativa apenas a questões práticas, tendo como objetivo último, igualmente, o mercado de trabalho. Concomitantemente, há também uma preocupação - à semelhança da Escola Nova com aquilo que é da vida empírica dos indivíduos, dando um enfoque na vida cotidiana e, também, naquilo que os estudantes desejam aprender. Dessa forma, a prática social aqui defendida está vinculada a uma acepção calcada na vida prática, cotidiana, sem que a preocupação com a reflexão teórica, propulsora de abstrações e da formação da consciência, ganhe o devido espaço que almejamos quando defendemos uma educação transformadora.

\subsection{A pedagogia histórico-crítica}

Apresentamos, por fim, a pedagogia histórico-crítica, por ser a teoria pedagógica que assumimos como estofo nesta discussão ${ }^{2}$. Fundada pelo professor e pesquisador Dermeval Saviani, essa tendência tem como grande obra de apresentação o livro Escola e democracia, o qual teve sua primeira publicação no ano de 1983. Na obra em questão, o autor esquadrinha os principais pressupostos de sua teoria, apontando para a necessidade de se superar o que ele denomina curvatura da vara. Ao expor as tendências por ele apontadas como mantenedoras do modo de exploração vigente e refletindo sobre como as teorias pedagógicas que se propuseram alternativas ao modelo tradicional de alguma forma acabam por manter, igualmente, o estado de coisas, sua proposta surge no sentido de tornar a escola um espaço de propulsão da transformação social. Em sendo uma "mediação no seio da prática social global” (SAVIANI, 2013, p. 421), o autor defenderá como a escola pode agir no processo de transformação da sociedade - não porque ela em si possa fazer tal virada, mas porque é nesse espaço que os homens e as mulheres da sociedade são formados, e são eles que, posteriormente, podem, a partir da compreensão das contradições da sociedade pautada no acúmulo do capital, reverter esse quadro social desigual em que vivemos. 
Assim, baseando-se na fundamentação do materialismo histórico-dialético e também na psicologia histórico-cultural, desenvolvida pela Escola de Vigotski, a pedagogia histórico-crítica tomará como ponto central a noção que tem atravessado este artigo: de prática social. Segundo Saviani (2012 [1983]; 2013), para que a escola cumpra o seu papel de formação humana integral, faz-se necessário que a prática social seja tomada como ponto de partida e ponto de chegada. Ela é o centro do processo pedagógico. Como ponto de partida, a prática social é comum tanto aos alunos quanto aos professores, porém com diferentes estatutos: enquanto os professores a compreendem de forma sintética, os alunos detêm uma noção da prática social que é sincrética, caótica.

Para que, ao fim, a prática social do ponto de chegada seja sintética também para os estudantes, é imperativo que eles se apropriem dos conhecimentos que são necessários para a compreensão da realidade. Reiteramos, portanto, a importância do conhecimento para essa perspectiva, já que, entendemos, é apenas por meio da compreensão da realidade, da efetivação entre teoria e prática, que os indivíduos podem de fato modificá-la. Esse processo pode, segundo Saviani (2012 [1983]), ser 'esquematizado' em cinco passos: o primeiro deles é a própria prática social, sincrética para os estudantes. O segundo é a problematização, que consiste em "detectar que questões precisam ser resolvidas no âmbito da prática social e, em consequência, que conhecimento é necessário dominar" (SAVIANI, 2012 [1983], p. 71). O terceiro passo é a instrumentalização e diz respeito ao momento em que os alunos irão se apropriar dos conteúdos necessários para a compreensão da prática social. Aqui, o professor ganha um destaque, já que será ele o responsável por transmitir tais conhecimentos acumulados historicamente. O quarto passo é o momento de catarse, que vem a ser a tomada de consciência, por parte dos estudantes, de que os conhecimentos apropriados são instrumentos para que eles possam agir em suas práticas sociais. Por fim, o quinto e último passo é a própria prática social, que, agora, é sintética também para os alunos ${ }^{3}$.

Ao adotar o fundamento marxista para sua teoria pedagógica, Saviani nos expõe elaborações teóricas e um método que propõe reverberar aquilo que já havíamos indicado no início deste artigo: a necessidade da vinculação entre teoria e prática para a compreensão da totalidade que é a realidade. Nessa perspectiva, os conteúdos trabalhados em sala de aula não estão restritos àquilo que é da ordem do empírico, mas, 
sim, aos conhecimentos ditos universais, elaborados pelo gênero humano ao longo da história, e que precisam ser apropriados pelas novas gerações, sobretudo aqueles do campo da ciência, da filosofia e da arte (DUARTE, 2016). Torna-se importante salientar que não excluímos, quando nos comprometemos com tal escopo teórico, os conhecimentos que são do cotidiano, os saberes locais, enfim. Nossa crítica recai sobre os moldes que circunscrevem os conteúdos escolares a apenas tais conhecimentos, o que, a nosso ver, acabam eximindo - especialmente das classes populares - a possibilidade de apreender os saberes tidos como clássicos (SAVIANI; DUARTE, 2012) e, como defende Saviani, “o dominado não se liberta se ele não vier a dominar aquilo que os dominantes dominam. Então, dominar o que os dominantes dominam é condição de libertação" (2012 [1983], p. 55).

Nesse sentido, compreendemos que a acepção de prática social assumida pela tendência histórico-crítica denota um significado absolutamente diferente das vertentes citadas anteriormente, sobretudo por conta do próprio fundamento filosófico que a ancora: o materialismo histórico-dialético ${ }^{4}$. Assumindo, de saída, tal vinculação filosófica, compreendemos que a escola não pode ter outro objetivo último que não seja a transformação do estado de coisas. Por isso, o próprio conceito de prática social toma aqui outro caráter: ele é o centro do processo pedagógico justamente porque o que se propõe é a modificação da práxis ${ }^{5}$, e não a manutenção desta, como outras tendências acabam reverberando tendo em vista os fundamentos conciliadores nos quais se ancoram.

\section{O CONCEITO DE PRÁTICA SOCIAL NA BASE NACIONAL COMUM CURRICULAR}

A partir da exposição e da compreensão das formas como a noção de prática social adentra o campo pedagógico, e dando o devido destaque para o caráter polissêmico de tal conceito, apresentamos, agora, breve análise da Base Nacional Comum Curricular (2017). O objetivo é analisar se há, ali, uma noção de prática social presente e se tal conceito toma uma acepção de caráter de manutenção ou de transformação do estado de coisas. Para tanto, a análise encontra-se dividida em duas seções: na primeira, atentar-nos-emos à seção introdutória da BNCC; na segunda, 
analisaremos a seção relativa ao ensino de Língua Portuguesa nos Anos Finais do Ensino Fundamental.

\title{
2.1 Análise da seção introdutória da Base Nacional Comum Curricular
}

A Base Nacional Comum Curricular, que teve sua primeira versão em 2015, seguida de uma segunda versão em 2016 e, por fim, a última para o Ensino Fundamental no final de 2017 e para o Ensino Médio em 2018, é um documento que, inicialmente produzido de forma democrática e com o auxílio de diversos profissionais da educação, emergiu nos últimos anos - como resposta a interesses de organizações mundiais e do empresariado - com o propósito de homogeneizar a Educação Básica do país. O objetivo, com tal documento, seria garantir que todos os estudantes, de todos os cantos do Brasil, pudessem ter acesso às mesmas aprendizagens. Trata-se, portanto, de um documento relacionado ao currículo das escolas, já que a preocupação recai sobre o que os alunos devem aprender. Tal como exposto nas primeiras páginas:

\begin{abstract}
A Base Nacional Comum Curricular (BNCC) é um documento de caráter normativo que define o conjunto orgânico e progressivo de aprendizagens essenciais que todos os alunos devem desenvolver ao longo das etapas e modalidades da Educação Básica, de modo a que tenham assegurados seus direitos de aprendizagem e desenvolvimento, em conformidade com o que preceitua o Plano Nacional de Educação (PNE). (BRASIL, 2017, p. 7)
\end{abstract}

Tomando como estofo legal as Diretrizes Curriculares Nacionais da Educação Básica (DCN, 2013) e a Resolução CNE/CP No $2^{6}$ (2017), a BNCC estabelece como escopo teórico a noção de competências. No documento, tal conceito é definido como “a mobilização de conhecimentos (conceitos e procedimentos), habilidades (práticas, cognitivas e socioemocionais), atitudes e valores para resolver demandas complexas da vida cotidiana, do pleno exercício da cidadania e do mundo do trabalho" (BRASIL, 2017, p. 8). Podemos afirmar, portanto, que há uma evidente vinculação com a pedagogia das competências, anteriormente apresentada, e que, em sendo a vinculação entre os conhecimentos e as habilidades relativas à vida dos estudantes já posta de saída, poderíamos apontar, já, aí, uma possível predominância da noção de prática social na proposta que a BNCC instaura. Uma prática social que, certamente, corresponderá aos pressupostos da pedagogia de Perrenoud (1999). 
No âmbito da relevância que as competências ganham no documento, são apresentadas dez competências gerais que deverão ser o foco da educação. Dada sua extensão, não listaremos todas as dez referidas competências, mas destacamos as quatro primeiras, já que estão elas diretamente atreladas à discussão aqui levantada, uma vez que apontam, em alguma medida, para a relação entre os conteúdos e a vida dos sujeitos:

I. Contextualizar os conteúdos curriculares, identificando estratégias para apresentá-los, representá-los, exemplificá-los, conectá-los e torná-los significativos, com base na realidade do lugar e do tempo nos quais as aprendizagens se desenvolvem e são constituídas; II. Decidir sobre formas de organização dos componentes curriculares [...]. III. Selecionar e aplicar metodologias e estratégias didático-pedagógicas diversificadas [...]. IV. Conceber e pôr em prática situações e procedimentos para motivar e engajar os estudantes nas aprendizagens. (BRASIL, 2017, p. 6, grifos nossos)

Podemos afirmar que a noção de prática social seguramente aparece com certa força nas competências que devem ser o fio condutor do ensino. No entanto, cabe ressaltar que essa prática está largamente associada a questões empíricas, mesmo porque a própria pedagogia das competências não coloca em foco os conhecimentos universais, mas, sim, conteúdos que tangem questões relacionadas ao dia a dia, à convivência, ao trabalho. Além disso, ao analisar as competências gerais, podemos identificar uma nítida vinculação da proposta da $\mathrm{BNCC}$ com as pedagogias do aprender a aprender, já que há destaque para a relevância em aprender a questionar, a criar hipóteses, a analisar fatos, enfim, em tornar-se um pesquisador. Uma relação, portanto, com a tendência da Escola Nova, apresentada anteriormente, e que também pauta o ensino em questões relativas à vida cotidiana dos sujeitos.

Para além da vinculação à vertente nova, é possível destacar, também, o estofo da pedagogia tecnicista no documento em questão. Essa centralidade na vida puramente prática, na Base, é também reafirmada quando se expõe que:

[...] as decisões pedagógicas devem estar orientadas para o desenvolvimento de competências. Por meio da indicação clara do que os alunos devem "saber" (considerando a constituição de conhecimentos, habilidades, atitudes e valores) e, sobretudo, do que devem "saber fazer" (considerando a mobilização desses conhecimentos, habilidades, atitudes e valores para resolver demandas complexas da vida cotidiana, do pleno exercício da cidadania e do mundo do trabalho), a explicitação das competências oferece 
referências para o fortalecimento de ações que assegurem as aprendizagens essenciais definidas na BNCC. (BRASIL, 2017, p. 13, grifos nossos)

$\mathrm{O}$ mundo do trabalho ganha um destaque bastante importante na BNCC e aparece justamente para valorar aquilo que é do campo do fazer, do manual, do prático. Vale ressaltar que, quando tomamos o estofo do materialismo histórico-dialético para a discussão, compreendemos que não se faz possível separar aquilo que é da ordem puramente prática daquilo que é do campo teórico. Nas palavras de Gramsci: "não existe atividade humana da qual se possa excluir toda intervenção intelectual, não se pode separar o homo faber do homo sapiens" (GRAMSCI, 1968, p. 7). Quer dizer, afirmamos que toda atividade, por mais manual que seja, envolve alguma capacidade de abstração. No entanto, quando teorias pedagógicas e documentos basilares - incluída aí a BNCC - focam apenas em questões que tangem a vida prática, eximindo a importância da atividade teórica e, portanto, a importância do conhecimento, a escola acaba por não facultar aos estudantes tal compreensão dialética da própria prática social, dispensando do processo educativo uma possível consciência histórica e de classe dos sujeitos (SANTOS, 2020).

Nesse sentido, a BNCC, documento que visa uniformizar o ensino brasileiro, acaba por priorizar as competências que devem ser desenvolvidas, de modo que os conteúdos não se colocam como componentes importantes nesse processo. Eles estão, como já afirmado, apenas a serviço das competências predefinidas. Podemos afirmar, assim, que, enquanto as competências estão postas e são comuns a todos, o currículo, isto é, o caminho para que tal aprendizagem ocorra, é diverso. É diverso, portanto, o conteúdo a ser trabalhado em sala - cabe à cada instituição definir o que melhor se adequa àquela realidade.

Dessa forma, tais colocações indicam o entrave que se pretendia destacar quando abordamos o fato de cada tendência pedagógica e de os documentos assumirem a noção de prática social e a importância do conhecimento de modos distintos. Quer dizer, ao procurarmos identificar a forma como a noção de prática social se insere na BNCC, percebemos que há, sim, uma reiteração bastante marcada da relevância em serem relacionados os conteúdos apreendidos em sala de aula e a vida dos sujeitos. Mas é importante dizer que, ao focar apenas na vida imediata, cotidiana, a prática social acaba por colocar em foco questões sobretudo do aprender a fazer. Torna-se, portanto, uma 
prática incapaz de alçar a consciência de classe nos estudantes uma vez que, ao serem priorizadas questões do mundo empírico, é posta de lado a formação intelectual dos sujeitos e, dessa forma, a capacidade de abstração teórica do mundo.

Assim, ao se valorizarem os aprendizados que tendem ao campo utilitário, à vida operativa, ao fazer, acaba-se por instaurar uma formação que, como nos aponta Vázquez (2011), visa apenas à manutenção da consciência ingênua, compreendida como uma consciência comum porque presa à espontaneidade das relações, não sendo capaz de ultrapassar a aparência da vida social. Dessa forma, instaurada, na BNCC, uma prática social que não traz a vinculação entre teoria e prática, entre objetivação e apropriação (DUARTE, 2013), compreendemos que tal documento deixa de instaurar a compreensão da vida social como algo histórico e condicionado pelas ações humanas e que, portanto, é passível de transformação. Quando o foco recai sobre a adequação da vida dos sujeitos à sociedade que já está posta, a manutenção desta acaba também por ser assegurada - objetivo que, julgamos, não deveria ser o da escola.

\subsection{Análise da seção relativa ao ensino de Língua Portuguesa nos Anos Finais}

A partir da breve análise referente à Introdução da BNCC, com destaque para o estofo teórico que baliza tal documento, passemos, agora, nosso olhar para a seção que se refere ao ensino de Língua Portuguesa. Vale ressaltar, antes, que a Base é composta por cinco áreas do conhecimento, sendo elas: 1) Linguagens; 2) Matemática; 3) Ciências da Natureza; 4) Ciências Humanas; 5) Ensino Religioso e que, dentro da área de Linguagens há, ainda, outra divisão, composta pelas seguintes subáreas: Língua Portuguesa, Arte, Educação Física e Língua Inglesa. Dado o escopo deste trabalho, analisaremos especificamente a subárea de Língua Portuguesa, sobretudo no que tange aos Anos Finais do Ensino Fundamental.

O ensino de LP, na concepção que perpassa a Base, toma como grande fio condutor do processo educativo o trabalho com os gêneros do discurso, compreendendo a língua como fruto das práticas de linguagens, as quais devem ser ampliadas pelos estudantes. Tal proposta de ensino tem seu escopo teórico alinhavado à teoria discursiva do Círculo de Bakhtin (1997 [192?]) e compreende, dessa forma, que o estudo da língua 
deve ser tomado a partir de um viés que estabelece a interação social como peça fundamental. Uma noção de prática social já aparece, portanto, de saída.

Por assim dizer, vimos como a ideia central é de que as aulas se estruturem com foco nos gêneros do discurso, os quais emergem na vida cotidiana dos indivíduos e que precisam ser apropriados. Essa noção irá perpassar toda a subárea de LP, dos primeiros anos até o Ensino Médio. No que se refere especificamente à seção dos Anos Finais do Ensino Fundamental, o enfoque dado é o seguinte:

\begin{abstract}
Aprofunda-se, nessa etapa, o tratamento dos gêneros que circulam na esfera pública, nos campos jornalístico-midiático e de atuação na vida pública. No primeiro campo, os gêneros jornalísticos - informativos e opinativos - e os publicitários são privilegiados, com foco em estratégias linguísticodiscursivas e semióticas voltadas para a argumentação e persuasão. Para além dos gêneros, são consideradas práticas contemporâneas de curtir, comentar, redistribuir, publicar notícias, curar etc. e tematizadas questões polêmicas envolvendo as dinâmicas das redes sociais e os interesses que movem a esfera jornalística-midiática. (BRASIL, 2017, p. 136)
\end{abstract}

Em relação ao trabalho com os gêneros do discurso, há diversas indicações e proposições sobre a forma como esse trato deve se realizar em sala de aula. É acentuada a necessidade de desenvolvimento de habilidade de argumentação e de persuasão por parte dos alunos, assim como a importância do comprometimento com as informações e com aquilo que é tido como verdadeiro, tendo em vista sobretudo as fake news, dada a forma como estas têm permeado e influenciado a vida em sociedade. Questões sobre discurso de ódio e sobre o respeito pelo outro também são levantadas, assim como a relevância de promover uma consciência de consumidor. Há, também, uma preocupação com os gêneros legais e normativos, com o intuito de que, ao trabalhar com tais textos, os alunos possam desenvolver "uma consciência dos direitos, uma valorização dos direitos humanos e a formação de uma ética da responsabilidade (o outro tem direito a uma vida digna tanto quanto eu tenho)" (BRASIL, 2017, p. 137). Enfim, os campos de conhecimento apresentados, até aqui, aparecem de forma bastante vinculada à vida operativa e utilitária dos indivíduos, já que, ainda que contenham temas importantes, estão voltados estritamente para questões do cotidiano, de forma que a própria noção de prática social já aparece, aí, vinculada a uma acepção empírica.

Seguindo essa lógica, são apresentados, também, os conhecimentos relativos às práticas investigativas, que se referem à capacidade de reelaborar conhecimentos a 
partir de textos-sínteses, como gráficos, esquemas, resumos, tabelas etc. O trabalho, aqui, seria com gêneros discursivos que auxiliam na organização e no processamento dos conteúdos que serão alvo de pesquisa dos estudantes. Um campo voltado, então, para aquilo que apontamos como a noção de aprender a aprender, já que preocupado com a capacidade de o aluno aprender sozinho. Ao fim, há ainda a indicação do campo artístico-literário, o qual "trata-se de possibilitar o contato com as manifestações artísticas em geral, e, de forma particular e especial, com a arte literária e de oferecer as condições para que se possa reconhecer, valorizar e fruir essas manifestações" (BRASIL, 2017, p. 138). Aqui há um acento bastante marcado na preocupação de que a arte se torne um objeto de fruição e que os alunos, por meio dela, sejam capazes "de se implicar na leitura dos textos, de 'desvendar' suas múltiplas camadas de sentido, de responder às suas demandas e de firmar pactos de leitura” (BRASIL, 2018, p. 138). Mesmo que a arte não seja tomada em uma esfera utilitária, torna-se relevante acentuar que, ao tomar o escopo artístico pelo viés do prazer, a BNCC acaba, também, eximindo dos alunos a capacidade de compreender as relações mais complexas desse campo que, quando tomado pelo ideário histórico-cultural, ganha outros contornos ${ }^{7}$.

Quando se trata da relevância do ensino metalinguístico nas aulas de LP, vimos como a Base procura manter a proposta calcada nos pressupostos apresentados anteriormente: se a língua é produto das interações verbais, seu ensino deve partir dessas mesmas práticas. Nesse sentido,

\footnotetext{
Os conhecimentos sobre a língua, as demais semioses e a norma-padrão não devem ser tomados como uma lista de conteúdos dissociados das práticas de linguagem, mas como propiciadores de reflexão a respeito do funcionamento da língua no contexto dessas práticas. (BRASIL, 2017, p. 139)
}

Observamos, assim, um rompimento bastante evidente com concepções de ensino de língua anteriores, as quais tomavam o ensino da gramática como polo central do processo educativo, ou, até mesmo, como o único objeto de conhecimento a ser trabalhado. Ademais, destacamos o fato de que, ao tomar uma concepção de língua que a compreende a partir de seus contextos de uso, a educação linguística, na BNCC, ganha um contorno bastante social, de modo que se torna possível afirmar que está voltada para a prática social dos sujeitos. 
Todavia, como temos procurado destacar, ao se falar em prática social faz-se necessário desvelar quais são as acepções que essa noção toma, a partir dos fundamentos que a ancoram. Quer dizer, embora haja, na Base, um movimento de tomar a língua sob um prisma distinto da tradição normativista, podemos depreender as noções que já apareceram na introdução da BNCC aqui também expostas. Isso porque, mesmo compreendendo que há uma mudança de enfoque no ensino de LP, a língua permanece apresentando, em alguma medida, um caráter instrumentalizador ${ }^{8}$, já que a proposta é que os estudantes reconheçam os seus contextos de uso, as relações entre a forma e as esferas de comunicação, enfim. Não vemos um trato com a língua que extrapole esse sentido de ferramenta, de forma que os alunos pudessem percebê-la como fruto da atividade humana.

Britto (2012), ao definir a língua como "um fenômeno de ordem histórica e [que], como tal, realiza-se e produz-se em função do trabalho humano" (BRITTO, 2012, p. 63), irá se contrapor às concepções pedagógicas que tendem a colocar questões da ordem "certo" ou "errado", "adequado" ou "inadequado" como oposições simplificadoras que não dão conta de abarcar todas as relações que circundam o domínio da língua escrita. Isto é, o autor aponta para uma discussão sobre como as tendências que se colocam como alternativas à Escola Tradicional acabam por perder de vista as relações de poder (e de classe) que estão impostas quando se pretende levantar discussões sobre o que é padrão ou não, ou sobre um uso de língua que acaba preso às questões cotidianas, ao uso imediato, sem ultrapassá-lo, sem reconhecer a língua como uma elaboração complexa criada pelos homens. Nesse sentido, indo ao encontro da discussão aqui levantada, Britto (2012) assinala o fato de as tendências pedagógicas e as teorias sobre o ensino de língua acabarem por deixar em segundo plano a importância do conhecimento para os estudantes. Especificamente sobre a pedagogia das competências, tendência balizadora da BNCC, o autor afirma que

Na perspectiva da educação de competências, o que está em foco não é o conhecimento, mas a capacitação genérica, de forma a tornar a pessoa apta para agir em conformidade com as determinações do sistema. Nessa lógica, haveria na sociedade contemporânea "novas demandas" de conhecimento, em especial no que concerne ao domínio relativo da leitura (e secundariamente de redação) para corresponder às situações práticas mediadas pela escrita. (BRITTO, 2012, p. 89-90) 
Compreendemos que, ao serem tomados os lemas do aprender a fazer e do aprender a aprender, estando ambos associados, em alguma medida, à tendência das competências, a BNCC apresenta uma proposta que tem em vista o desenvolvimento, por parte dos alunos, de questões relativas à vida em sociedade, para que possam eles exercer suas atividades de cidadão e de trabalhador (BRASIL, 2017). Por assim dizer, o trabalho manual e a vida prática-operativa ganham uma centralidade muito marcada nesse documento, de forma que o conhecimento e o trabalho intelectual acabam por ser secundarizados.

No que tange ao ensino de LP nos Anos Finais do Ensino Fundamental, é possível perceber a forma como tais pressupostos são mantidos, já que há uma preocupação bem evidente em se ensinar língua para a vida prática; um ensino, portanto, que tende sobretudo à instrumentalização e à operação desses indivíduos frente às manifestações linguísticas. Dessa forma, não encontramos, na BNCC, uma reflexão acerca das relações entre o uso da língua e as objetivações humanas, enfim, o apontamento da língua como fruto do trabalho ${ }^{9}$ humano e como condição para o desenvolvimento do psiquismo.

Se quiséssemos apontar, por fim, uma educação linguística que se colocasse como humanizadora, tal perspectiva deveria alçar uma ação pedagógica que levasse

[...] o estudante a perceber a língua e a linguagem como fenômenos históricos complexos, a compreender seu funcionamento, usos e formas, bem como a saber usá-la com propriedade nas modalidades oral e escrita [de forma que pudesse ele] estudar e aprender e viver sua subjetividade. (BRITTO, 2012, p. 84)

O foco do ensino seria, então, um estudo que envolvesse as questões práticas, os usos, a experiência dos sujeitos, mas que fosse somada à reflexão acerca do conhecimento linguístico, já que é a língua "um objeto central na organização da cultura e da sociedade” (BRITTO, 2012, p. 97). Na busca por ultrapassar uma noção puramente instrumentalizadora ou pragmática de ensino linguístico, voltado apenas para questões da vida operativa, a educação linguística que projetamos teria como pressuposto incorporar e ultrapassar as questões puramente práticas, tal como vimos na BNCC. Um ensino de língua que se quisesse transformador traria relações entre objetivação e apropriação, entre teoria e prática, para que esse conhecimento pudesse ser, também ele, um instrumento - em seu sentido mais amplo - para o reconhecimento de que os 
estudantes são os criadores da realidade e, portanto, podem ser os indivíduos propulsores da transformação que apontamos.

\section{CONSIDERAÇÕES FINAIS}

Ao analisar o atual documento balizador do ensino nacional, a BNCC (2017), e ao resgatar as tendências que, de alguma forma, acabam reverberando na construção da Base, procuramos destacar como há, no campo pedagógico e também no ensino de LP, uma noção de prática social que acaba pairando em todas as perspectivas apresentadas. Nosso propósito, no entanto, foi apontar para o fato de que, mesmo apresentando, aparentemente, a mesma faceta, tal conceito acaba por reverberar, em sua essência, projetos educativos distintos, possuindo, portanto, acepções que divergem completamente. Como vimos, a BNCC apresenta uma fundamentação calcada na pedagogia das competências e, portanto, volta-se para a vida prática e utilitária dos sujeitos, o que acaba restringindo, da formação escolar, o devido espaço para os conhecimentos sistematizados, que foram produzidos pelas gerações anteriores e que necessitam ser apropriados pelas gerações atuais ${ }^{10}$. Mais do que isso: ao reverberar uma educação linguística que privilegia o mercado de trabalho e a adequação desses indivíduos à sociedade em que vivemos, tanto as tendências hegemônicas (a tradicional, a nova, a tecnicista e a das competências aqui resgatadas) quanto os documentos por elas balizados assumem, ao fim, um projeto que considera somente a manutenção da referida prática social.

Por fim, procuramos destacar como se faz fundamental que educadores e pesquisadores possuam uma compreensão acerca do estofo filosófico e teórico que está por trás de cada orientação pedagógica. Aos que pretendem fazer da escola um espaço de revolução, fica nosso convite para esse olhar atento às noções que, embora pareçam homogêneas, acabam por alçar diferentes projetos de formação humana e, portanto, de sociedade. 


\section{Referências}

BAKHTIN, M. Estética da Criação Verbal. Tradução do francês por Maria Ermantina Galvão G. Pereira. São Paulo: Martins Fontes, 1997 [192?].

BRASIL. Ministério da Educação. Base Nacional Comum Curricular. Brasília: Ministério da Educação, 2017. Disponível em: http://basenacionalcomum.mec.gov.br/. Acesso em: 13 jun. 2020.

BRASIL. Ministério da Educação. Secretaria de Educação Básica. Secretaria de Educação Continuada, Alfabetização, Diversidade e Inclusão. Conselho Nacional da Educação. Diretrizes Curriculares Nacionais Gerais da Educação Básica. Brasília: MEC, SEB, DICEI, 2013.

BRASIL. Ministério da Educação. Conselho Nacional de Educação. Conselho Pleno. Resolução $C N E / C P n^{\circ} 2$, de 22 de dezembro de 2017. Institui e orienta a implantação da Base Nacional Comum Curricular, a ser respeitada obrigatoriamente ao longo das etapas e respectivas modalidades no âmbito da Educação Básica. Brasília: Ministério da Educação, 2017.

BRITTO, L. P. L. Contra o consenso: cultura escrita, educação e participação. Campinas, SP: Mercado de Letras, 2003.

BRITTO, L. P. L. Inquietudes e desacordos: a leitura além do óbvio. Campinas, SP: Mercado de Letras, 2012.

DUARTE, N. Individualidade para si. Campinas, SP: Autores Associados, 2013.

DUARTE, N. Os conteúdos escolares e a ressureição dos mortos: contribuição à teoria histórico-crítica do currículo. Campinas, SP: Autores Associados, 2016.

DUARTE, N. Sociedade do conhecimento ou sociedade das ilusões? Campinas, SP: Autores Associados, 2018.

GRAMSCI, A. Os intelectuais e a organização da cultura. Rio de Janeiro: Ed. Civilização Brasileira S.A., 1968.

LÖWY, M. As aventuras de Karl Marx contra o Barão de Münchhausen: marxismo e positivismo na sociologia do conhecimento. São Paulo: Cortez, 2013.

MARX, K. Manuscritos econômico-filosóficos. São Paulo: Boitempo, 2010.

MARX, K. O Capital: crítica da economia política: Livro I: o processo de produção do capital. Trad. Rubens Enderle. 2. ed. São Paulo: Boitempo, 2017 [1867].

PERRENOUD, P. Construir as competências desde a escola. Porto Alegre: Artes Médicas Sul, 1999. 
SANTOS, L. M. Mas que prática social é esta? Diferentes acepções e implicações para o ensino de línguas. 2020. 135p. Dissertação (Mestrado em Linguística) - Programa de Pós-Graduação em Linguística, Universidade Federal de Santa Catarina, Florianópolis, 2020.

SAVIANI, D. Escola e democracia. 42 ed. Campinas, SP: Autores Associados, 2012 [1983].

SAVIANI, D. História das ideias pedagógicas no Brasil. Campinas, SP: Autores Associados, 2013.

SAVIANI, D. Marxismo, Educação e Pedagogia. In: SAVIANI, D.; DUARTE, N. (Org.). Pedagogia histórico-crítica e a luta de classes na educação escolar. Campinas, SP: Autores Associados, 2012.

SAVIANI, D.; DUARTE, N. A formação humana na perspectiva histórico-ontológica. In: SAVIANI, DUARTE, N. (Org.). Pedagogia histórico-crítica e luta de classes na educação escolar. Campinas, SP: Autores Associados, 2012.

SUCHODOLSKI, B. A pedagogia e as grandes correntes filosóficas. Lisboa: Livros Horizonte, 1972.

TONET, Ivo. Método científico: uma abordagem ontológica. São Paulo: Instituto Lukács, 2013.

VÁZQUEZ, A. S. Filosofia da práxis. São Paulo: Expressão Popular, 2011.

Recebido em: 04/01/2021

Aceito em: 05/02/2021

\footnotetext{
${ }^{1}$ Vale ressaltar que a noção de liberdade, aqui, nada se assemelha àquela defendida pelos pressupostos do materialismo histórico-dialético. A noção de seres livres do mundo capitalista é, na verdade, uma forma de escamotear as contradições impostas pelo próprio modo de organização social, não facultando aos indivíduos a consciência (de classe) que temos defendido.

${ }^{2}$ Importa salientar que Saviani (2012 [1983]; 2013) também aborda outras correntes de cunho crítico - tal como a tendência crítico-reprodutivista, que não chegou a converter-se em prática pedagógica de fato -, as quais irão se distanciar de diversas maneiras das perspectivas aqui apresentadas. Dada a extensão deste trabalho, optamos por abordar apenas as correntes que mais se relacionam com o objeto de análise.

${ }^{3}$ Cabe destacar que os passos propostos por Saviani (2012 [1983) não são moldes estanques, mas, sim, movimentos dialéticos que, ao longo do processo educativo, vão se (re)estruturando.
} 


\begin{abstract}
${ }^{4}$ Podemos afirmar que a essência desse fundamento está pautada na crítica da sociedade premida pelo acúmulo do capital e na defesa por uma transformação radical da forma como vivemos, almejando, portanto, uma sociedade muito mais justa e igualitária. Compreendendo o materialismo histórico-dialético como estofo filosófico, teórico e metodológico, adotamos tal perspectiva neste trabalho por compreendemos que o espaço escolar pode ser também um local que promova tal transformação.
\end{abstract}

${ }^{5}$ A filosofia da práxis, formulada teoricamente por Antônio Gramsci, diz respeito ao fato de que a realidade é criada pelos homens por meio de um processo que vai da objetividade para a subjetividade, num movimento dialético. É nessa teoria que nos embasamos quando assumimos a importância do conhecimento para a transformação social, já que, para Gramsci (1968), a relação entre teoria e prática é o próprio fundamento de uma práxis - isto é, da própria realidade - que se coloque como revolucionária.

${ }^{6}$ Em Santos (2020), o conceito de prática social é analisado também nesses documentos.

${ }^{7}$ Para a psicologia histórico-cultural, a arte é, também, uma objetivação criada pelo homem e que, ao ser apropriada pelas novas gerações, promove o desenvolvimento da segunda natureza humana, auxiliando no processo de desenvolvimento das funções psíquicas superiores e contribuindo, portanto, para a formação humana que abarque aquilo que é do campo do universal, do campo do gênero humano (cf. DUARTE, 2016).

8 A instrumentalização, aqui, aparece como um sinônimo de pragmático, de utilitário, não correspondendo, portanto, à noção de língua como instrumento para a transformação e formação humana que a teoria histórico-cultural defende.

${ }^{9}$ Utilizamos a categoria trabalho a partir do fundamento marxista e não na acepção que ela toma na sociedade do capital. Para Marx (2010), o trabalho diz respeito à capacidade unicamente humana de transformar a natureza a nosso favor, através de um processo de prévia-ideação. É, portanto, o trabalho o próprio propulsor da práxis.

${ }^{10}$ Uma vez que compreendemos o conhecimento sistematizado, sobretudo do campo científico, filosófico e artístico, peça fulcral para a formação humana dos indivíduos, já que propulsores de uma consciência, por parte dos indivíduos, de que são eles criadores da realidade social, julgamos que, para uma abordagem que se propusesse menos conservadora do estado de coisas, a BNCC (2017) poderia tratar acerca dos conteúdos com outros contornos. Procuramos evidenciar como a preocupação, para tal documento, é de que os sujeitos se adequem ao mercado de trabalho e à vida nessa forma de sociabilidade, e como, para tanto, o que os alunos irão aprender de fato acaba ficando muito circunscrito à vida empírica. Para que seu objetivo último fosse outro, os conhecimentos destacados - da ciência, da arte e da filosofia - certamente deveriam apresentar uma centralidade muito mais marcada, tendo em vista a correlação entre teoria e prática que almejamos - calcada na filosofia da práxis, e, portanto, objetivando uma consciência dos sujeitos acerca das contradições que permeiam nossa sociedade. Com uma escolarização voltada apenas para a cotidianidade, são eximidas dos estudantes as possibilidades de que eles se compreendam como sujeitos históricos, individuais mas também coletivos, e que, em sendo produtores da realidade, podem certamente modificar a forma social que vivemos. 